\title{
Relationship between Hospital Nurses' Perception of Organizational Justice and Organizational Commitment
}

\author{
Ebtehal L. Omar, Nursing Inspector \\ Directorate of Health Affairs, El Behera Governorate
}

\author{
Azza Hassan Mohamed Hussein, Assistant Professor \\ Nursing Administration, Faculty of Nursing, Alexandria University \\ Rehab Gamel Hussein, Lecturer \\ Nursing Administration, Faculty of Nursing, Alexandria University
}

\begin{abstract}
Perception of organizational justice has been related to numerous other organizational factors, including organizational commitment. Yet, less is known about mechanisms linking organizational justice to organizational commitment. Objective: Investigate the relationship between nurses' perception of organizational justice and commitment to their organization, and whether differences in nurses' perception in relation to organizational justice and organizational commitment are different between two hospitals. Settings: Two health care organizations (Damanhour National Medical Institute and Kafr-El Dawar General Hospital) in ELBehera governorate. Subjects: All nurses who were available and willing to participate in the study during the time of data collection in the two hospitals $(N=317)$. Of these, 280 completed and returned the questionnaires. Tools: Two tools were used; Organizational Justice Scale and Organizational Commitment Scale. Results: Regression model indicates that nurses' perception of distributive justice and procedural justice were positively associated with nurses' affective commitment and normative commitment. Only interactional justice was significantly associated with affective commitment. There were significant differences between nurses' perception of the overall organizational justice $(Z=2.1, p=.033)$ and overall organizational commitment $(Z=2.4, p=.018)$ between studied hospitals. Conclusion: The study indicates the importance of both interactional and procedural justice for nurses' commitment. Recommendations: Future studies need to better define the specific components of distributive justice and means to enhance them in order to strengthen organizational commitment among nurses.
\end{abstract}

Keywords: Organizational justice, Organizational commitment, Equation modeling.

\section{Introduction}

Organizational psychology research has examined organizational justice as well as associated outcomes such as employees' commitment to their organizations. Perception of justice could be used as a predictor for employees' commitment to their organization. It is important for hospitals to maintain fair work environment in order to improve patient care and hospital performance as well as enhance nurses' commitment $^{(1)}$. Chen et al. (2015) found that the organizational justice perceived by nurses has a significant positive association with their organizational trust and organizational identification. They also found that organizational trust in the hospital and organizational identification are positively associated with organizational commitment. However, it was reported that simply adopting practice of justice is not the best method to increase nurses' commitment; it is necessary to focus on the impact of justice on nurses' commitment ${ }^{(2)}$. 
Therefore, this study aimed to investigate how the organizational justice perception could encourage nurses to commit themselves to their hospital.

Organizational justice originates from the equity theory of Tomblom (1990) ${ }^{(3)}$. It has three distinct variables; distributive justice, procedural justice and interactional justice $^{(4-6)}$. Generally, organizational scholars have empirical proof to distinguish the premises and ramifications of distributive justice, procedural justice and interactional justice $^{(7)}$.

According to Saks (2006), procedural justice refers to employees' perception of the fairness of the process used to allocate the resources while distributive justice considers an employees' perception of fairness as to how resources are actually distributed ${ }^{(8)}$. Interactional justice reflects the degree to which people are treated with politeness, dignity, and respect by authorities and third parties involved in executing procedures or determining outcomes $^{(9)}$. The study of Faheem and Mahmud (2015) revealed that procedural justice, distributive justice and interactional justice were significantly and reversely associated with counterproductive workplace behaviors and were positively correlated with job satisfaction $^{(10)}$. Folger and Konovsky (1989) found that distributive justice was reported to be more important compared to procedural justice in terms of satisfaction with pay. However, procedural justice accounted for more variations in organizational trust of supervisor and organizational commitment ${ }^{(11)}$.

Organizational commitment is "generally defined as loyalty to, identification with and a desire for involvement in an organization" ${ }^{(12)}$. Myer and Allen (1997) theorized organizational commitment by developing a tridimensional concept characterized by affective, continuance, and normative components $^{(13)}$. According to Gambino (2010) and Chang et al. (2015), affective commitment is strongly consolidated with nurses' experience of the emotional attachment to, and personal identification with, the nursing profession. Continuance commitment expresses an opportunistic thought to reduce loss of the perceived benefits of switching to another organization. Normative commitment refers to nurse's perceived ethical obligation and values related to loyalty and fidelity to remain in the organization. Therefore, nurses' affective commitment depicts their inner beliefs and values to practice, while normative commitment acts as an external system including social and environmental factors that motivate nurses to practice in their organizations. The continuance commitment refers to the overall costs to an employee to keep working in the $\operatorname{organization}^{(14,15)}$.

Many studies were developed to examine the relationship between organizational justice and organizational commitment in the context of other mediating variables, such as trust and identification ${ }^{(15)}$, staff job stress and job satisfaction $^{(16)}$. Also, some of these studies were limited to investigate some components of organizational justice (11) $^{(17)}$ and/or organizational commitment ${ }^{(17)}$. The latter study revealed that distributive and procedural justice had significant positive relationship with affective commitment, which in turn has a significant negative impact on turnover intention ${ }^{(17)}$. A study done by Zein ElDin and Abd El Rahman, (2013), found a significant positive association between pay equity and normative commitment ${ }^{(18)}$. Rezaiean et al. (2010) reported that organizational justice was a significant predictor to organizational commitment in nurses ${ }^{(19)}$.

\section{Aim of the Study}

This study aims to investigate the relationship between nurses' perception of organizational justice and commitment to their organizations, and examine the differences between nurses' perception in relation to organizational justice and organizational commitment at the studied hospitals. 


\section{Research Questions:}

- Is there a relationship between nurses' perception of overall organizational justice and their overall organizational commitment?

- Is there association between organizational justice dimensions and organizational commitment dimensions?

- What are the differences in nurses' perception of overall organizational justice and organizational justice dimensions between the two studied hospitals?

\section{Materials and Method}

\section{Materials}

Design: This is a descriptive correlational study.

Settings: Two health care organizations (Damanhour National Medical Institute and Kafr-El Dawar General Hospital) in ELBehera governorate, Egypt were selected for this study. Damanhour National Medical Institute is an academic hospital consists of eight surgical units, four medical units, and two intensive care units (ICUs). It is one of the largest governmental medical institutes in Egypt, and consists of 564 beds with wide range of health care services such as inpatient units, outpatient clinics, and acute care setting. The hospital also includes departments such as radiology, laboratory, pharmacy, blood banks, dietary, laundry, maintenance departments and other support services. The second hospital was Kafr EL Dawar General Hospital which is made up of four surgical units, three medical units, and two ICUs. The hospital is affiliated to the Egyptian Ministry of Health. It is equipped with 250 beds with different health care services including outpatient clinics, emergency and inpatient departments with different specialties, critical care units, and intensive care units. It also includes paramedical departments such as: blood bank, radiology, laboratory, pharmacy, dietary, laundry, and maintenance department.
Subjects: The study participants comprised all nurses who were available and willing to participate in the study during the time of data collection in the two hospitals $(\mathrm{N}=317)$. Of these, 280 completed and returned the questionnaires, representing a valid response rate of $88.3 \%$. The response rate was 159 out of $184(86.4 \%)$ for Damanhur National Medical Institute, comprised of 58 nurses in surgical units, 70 nurses in medical units, and 31 in intensive care units. At Kafr EL Dawar General Hospital, 121 out of 133 (90.9\%) responded and they represented 40 nurses working in surgical units, 39 nurses in medical units, and 42 in intensive care units.

\section{$\underline{\text { Tools: }}$}

\section{Tool I: Organizational Justice Scale}

Organizational Justice Scale was developed based on the work of Colquitt $(2001)^{(9)}$ and Niehoff and Moorman (1993) (20) to measure nurses' perception of organizational justice. It consists of 28 items grouped into three main components: distributive justice (10 items), procedural justice ( 8 items), and interactional justice (10 items). The responses were measured using 5-point Likert scale ranging from strongly agree (5) to strongly disagree (1); higher score indicates stronger perception of organizational justice.

\section{Tool II: Organizational Commitment} Scale

Organizational Commitment Scale developed by Allen and Mayer (1990) ${ }^{(21)}$ and used to assess nurses' perception of their organizational commitment. It included 24 items grouped into three main dimensions: affective ( 8 items), normative (8 items), and continuance (8 items). Responses were measured using 5-point Likert scale ranging from strongly agree (5) to strongly disagree (1). Negative items were reversely scored. Higher score indicates higher perceived organizational commitment. In addition, nurses' age, qualifications, total years working in the 
hospital and in the current unit were assessed.

\section{Method}

1. Permission to conduct the study was secured from the directors of the selected hospitals.

2. The two tools were translated into Arabic, and back-translated into English, and tested for their content validity by seven experts in relevant fields and they have advanced competency level in Arabic and English languages. Based on consensus opinions, necessary modifications were done in some questions included in the organizational justice scale.

3. Internal consistency was evaluated using Cronbach's alpha for scales assessing organizational justice and organizational commitment. Cronbach's alphas were high, .935 and .899 respectively, and the alpha error was 0.05 .

4. A pilot study was carried involving $10 \%$ of nurses $(\mathrm{N}=28)$ who were not included in the study in order to determine study feasibility, including design and questionnaire content.

5. The needed instructions were given to the participants before distribution of the questionnaires. Data were collected by one of the researchers and the questionnaires were hand delivered to each of the study participants in his/her work settings in the break time at morning and afternoon shift. It took between 15-25 minutes to respond to each tool. Data were collected over a period of four months, 2012.

\section{Ethical considerations:}

- The study was approved by the Institutional Review Board of the Alexandria University, Faculty of Nursing on 2012.

- After giving necessary information before the distribution of the questionnaires, informed consent was obtained from all participants.

- Confidentiality of data and participants' privacy and anonymity were assured.

\section{Statistical Analysis}

After data were collected they were reviewed, coded and fed to statistical software SPSS version 16. The statistical significance level was set at a two-tailed $\mathrm{p}$ value of less than .05. Descriptive statistics: included the mean with standard deviation and percentage to describe the scale and categorical data, respectively while median score percentage was used for skewed data as well as minimum (min) and maximum (max) scores were calculated. All scores were transformed into score percentage (\%) as follow: mean score percentage $\%=$ (the observed score / the maximum score) x 100 .

One-Sample Kolmogorov-Smirnov Test was used to analyze of numeric data, it is a procedure that compares the observed cumulative distribution function for a variable with a specified theoretical distribution which was the normal distribution at the current data (testing for distributional assumption for numerical data) then the following statistical analysis was done: a) Mann Whitney test: a procedure compares ranks (medians) for two independent groups of cases. It is like ttest but with skewed data. b) KruskalWallis test: it is a non-parametric statistical analysis used to compare mean/median ranks for more than two independent samples for quantitative data. c) Correlation analysis: correlation is used to test the nature and strength of relation between two quantitative/ordinal variables. The spearman correlation coefficient (rho) is expressed as the Person correlation coefficient. The sign of the coefficient indicates the nature of relation (positive/negative) while the value indicates the strength of relation as follow: Weak correlation for rho less than 0.25 , intermediate correlation for rho of value between $0.25-0.74$ and strong correlation for values between $0.75-0.99$. 
Structural equation modeling (SEM) has several advantages over traditional regression, which are particularly substantial to the current study. Structure equation model is a current statistical procedure for multi equation systems that include continuous latent variables, multiple indicators of concepts, errors of measurements, errors in equations, and observed variables. It was used for corelation between some latent variables (justice data) and outcome variables (commitment data) to identify the unique effect for each latent over each outcome keeping all other relations constant. The magnitude of effect is identified by a standardized regression coefficient for each latent variable. Also, the co-relation covariances between the latent variables are studied for multi-co linearity. One model was done to study the influence of the three organizational justice components on the three organizational commitment dimensions.

\section{Results}

\section{Characteristics of the participants}

The highest percentage of the nurses $(27.9 \%)$ was between 20 to less than 25 years old. More than half of nurses $(51.6 \%)$ had a Diploma of Secondary Technical Nursing School and 36.6\% had Baccalaureate of Science Degree in Nursing. Also, $42.9 \%$ of nurses had 5 to less than 10 years working in the hospital. About $48.6 \%$ of nurses had 5 to less than 10 years of experience in their current work unit.

Table (1) represents the actual Betas of the model depicted in figure 1 of the direct pathways linking organizational justice and organizational commitment. Standardized beta is used since it allows for easier comparisons between models. In predicting nurses' commitment, it is found that nurses' perception of distributive justice is associated significantly with affective commitment $(\beta=.320, p=.000)$ followed by normative commitment $(\beta=.234, p=.000)$. Insignificant association with continuance commitment $(\beta=.105, p=.114)$. Nurses' perception of procedural justice component is associated significantly with affective commitment $(\beta=.245, \mathrm{p}=.006)$ followed by normative commitment $(\beta=.252, \mathrm{p}=.010)$. Insignificant association is found in this respect with continuance commitment $(\beta=$ $.105, \mathrm{p}=.353)$. In addition, nurses' perception of interactional justice component is associated significantly only with affective commitment $(\beta=.201, \mathrm{p}=$ $.018)$. Insignificant associations are found between nurses' normative commitment ( $\beta=$ $.150, \mathrm{p}=.110)$, continuance commitment $(\beta=.087, p=.419)$ and their perception of interactional justice.

Table (2) illustrates that a statistical significant positive correlation between overall organizational justice and organizational commitment $(\mathrm{rs}=.581, \mathrm{p}=$ $.000)$. In addition, there were significant positive correlations between the three components of organizational justice (distributive, procedural and interactional justice), and all components of organizational commitment (affective, normative and continuance) except between distributive justice and continuance commitment $(\mathrm{rs}=.103, \mathrm{p}=.085)$.

Table (3) reveals that the median score percentage of the nurses' perception of the overall organizational justice was 51.4 and that nurses' overall commitment was 58.3. Nurses working at Damanhur National Medical Institute scored higher (53.8) than nurses working at Kafr- EL Dawar General Hospital (49.0) on the overall organizational justice with a statistical significant difference $(Z=2.1, p=.033)$ Furthermore, scores for nurses' perception on overall organizational commitment at Damanhur National Medical Institute (59.2) were higher than that of Kafr-EL Dawar General Hospital (57.5) with a statistical significant differences $(\mathrm{Z}=2.4, \mathrm{p}=.018$.) Scores of nurses' perception of distributive and interactional justice were significantly higher among those working at Damanhur National Medical Institute (46.0) and (62.0) than those at Kafr-EL Dawar General Hospital (42.0) and (60.0), $(\mathrm{Z}=2.3, \mathrm{p}=.021$ and $\mathrm{Z}=2.0, \mathrm{p}=.045)$ respectively. 
Moreover, the highest median score percentage of nurses' perception was found on interactional justice (61.0) followed by procedural justice (46.7) and distributive justice (44.0). Similar trend of results were found in the two studied hospitals. The median score percentage on the scale assessing affective commitment for nurses working at Damanhur National Medical Institute was significantly higher (44.4) than in Kafr-EL Dawar General Hospital (42.2), $(\mathrm{Z}=2.3, \mathrm{p}=.021)$. Also, the highest median score percentage for nurses, regardless of hospital, was found for continuance commitment (62.2), followed by normative commitment (51.1), and finally affective commitment (42.2). Similar trends were found within each of the studied hospitals.

\section{Discussion}

The findings of the present study showed that nurses perceived relatively low level of organizational justice and organizational commitment. However, the path analysis reveals that procedural justice and distributive justice are positively associated with nurses' organizational commitment (affective commitment and normative commitment); and interactional justice has a significant positive association with affective commitment only. These findings could be dissimilar to some extent with the outcomes of the matrix which indicate significant correlations between all components of organizational justice and organizational commitment except distributive justice and continuance commitment. The results of Raza et al. (2013) are in accordance with the findings of the present study as they found that the correlation matrix showed that each of distributive justice and procedural justice had positive and significant relationships with three components of organizational commitment (normative, continuance and affective commitment) ${ }^{(22)}$.

Furthermore, the results of Lambert and Hogan (2011) provide a fundamental contribution of correlations of distributive and procedural justice and organizational commitment in the workplace ${ }^{(23)}$.
Otherwise, the results of Rai (2013) inferred that interpersonal justice was not related to any attitude or behavior included in the study. Also, interpersonal justice has no significant association with any of the components of commitment ${ }^{(24)}$. In the present study, the SEM indicates that continuance commitment; which was the domain that received the highest scores on organizational commitment scale was not a significant predictor of any of the organizational justice components. One of the empirical findings of SEM used by Chen et al. (2015) showed that organizational justice experienced by nurses had a significant positive effect on their organizational commitment ${ }^{(2)}$. Meyer and Allen (1991) point out in their study that employees with a strong affective commitment will continue to be employed within an organization ${ }^{(25)}$. However, the direct relationship between components of organizational justice and organizational commitment using SEM is almost never discussed in the nursing literature, and healthcare organizations can develop a conducive approach to apply these concepts in managing the workforce to retain component labor and reduce quitting and increasing the organizational commitment of nurses, which require an effective hiringtraining-turnover process in healthcare providers, and thus enhancing the hospital performance.

On the contrary, a study done by Wiener at al. (2009), to examine how certified nursing assistants perceive low salaries associated with organizational commitment, reported that the participants relinquish their jobs because they did not feel respected or engaged in decisions of planning care of the clients or that they were part of the healthcare team ${ }^{(26)}$. According to Forbes-Thompson et al. (2007), sound nursing organizations are now using career ladders and empowering of nurses as a response of change in work culture to strengthen organizational commitment ${ }^{(27)}$. In the present study, some dimensions of justice are likely to be more stable than are others as nurses reported higher perception 
of interactional justice than the distributive and procedural justice. This could justify why nurses perceive continuance commitment to their hospital more than the other two types. It might be that organizational policies and standards contribute to ratings of low distributive justice among Egyptian nurses. The same appears to hold true for procedural justice, while interactional justice is rated more favorable.

Similar findings were reported by Lambert et al. $(2007)^{(16)}$. Otherwise, Jafari et al. (2011) found that procedural justice was the lowest organizational justice in nurses $^{(28)}$. Our findings confirm that nurses working at Damanhur National Medical Institute, perceived the distributive, interactional and overall organizational justice, and affective and overall organizational commitment higher than in nurses working at Kafr-EL Dawar General Hospital. The reasons for these systematic differences between the two hospitals remain to be determined. It might be that organizational structures, leadership, available resources contribute to these differences. However, it might also be that the way these two organizations value procedural and distributive justices differ and thus impact differentially on nurses' organizational commitments.

In addition, differences in resources, market positioning and patient needs between the two institutions might impact on these measures. An overall strength of the current study is that we included two hospitals and were thus able to determine similarities versus differences in important variables. Our results clearly show the importance of not generalizing findings since there might be substantial differences across healthcare organizations.

\section{Conclusion}

The previous findings demonstrate that nurses' perception of both organizational justice and organizational commitment are modest. Also, there are significant associations between most of the components of the two variables under study. Furthermore, the studied setting is a significant factor in the differences of nurses' perception of these variables as well as their components.

\section{Recommendations}

The followings are the main recommendations yielded by this study:

- Health care organizations would enhance nurses' commitment by initiating a set of fair practices such as treating them with respect, maintaining open communication, and listening carefully for their views.

- Hospitals can develop policies that maintain fair nurses' recruitment, increase their participation in decision making, provide frequent feedback, design a climate of fairness and trust, and create a competitive salaries system based on performance.

- Additional studies that follow qualitative design such as focus groups and observations are required to confirm these findings and add in-depth understanding of the studied variables. 


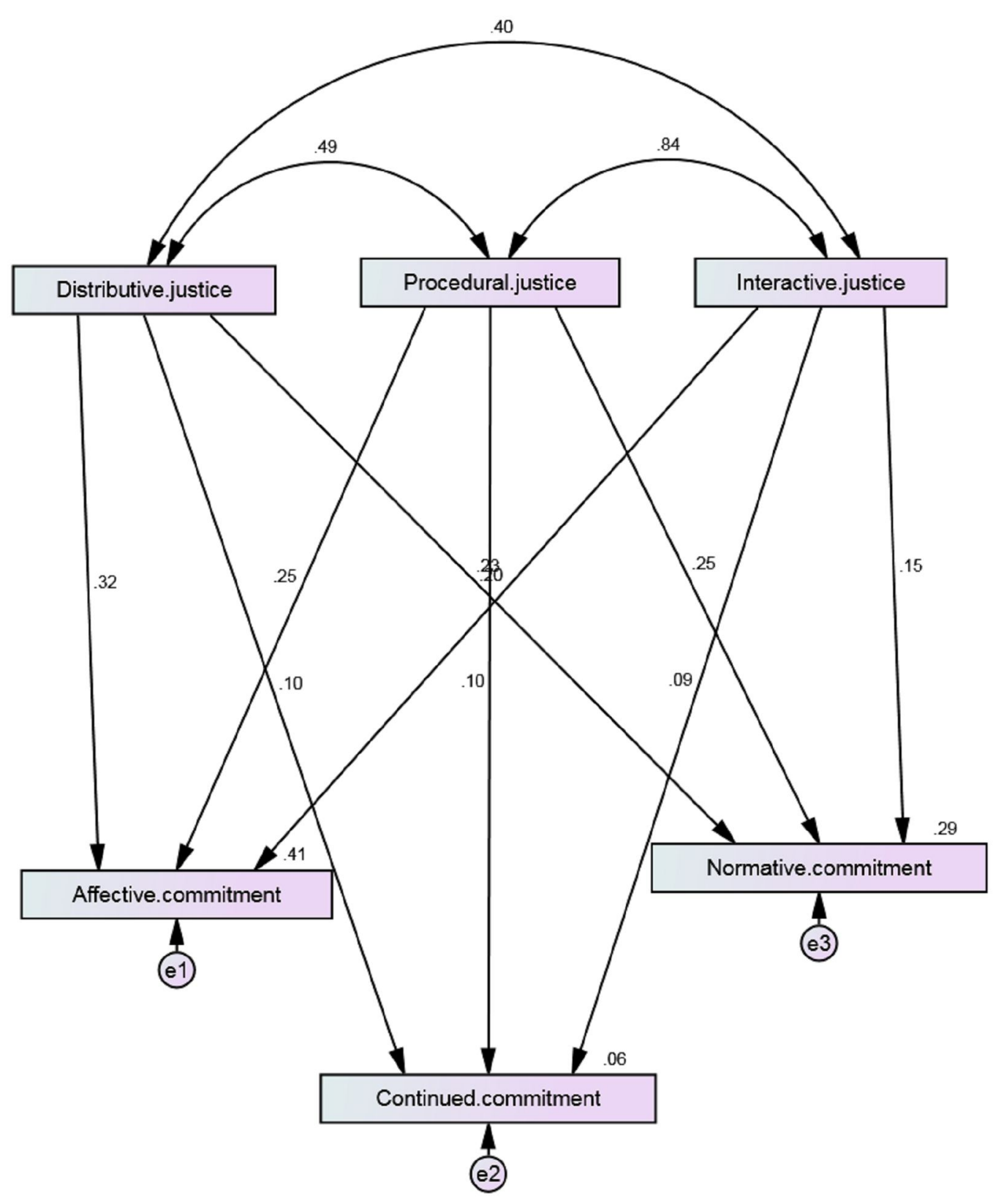

Figure 1: Regression model of the effect of components of organizational justice on organizational commitment components 
Table (1): Standardized regression weights for the effect of dimensions of organizational justice on organizational commitment dimensions

\begin{tabular}{|lll|cccc||}
\hline $\begin{array}{l}\text { Organizational } \\
\text { commitment dimensions }\end{array}$ & & $\begin{array}{l}\text { Organizational } \\
\text { justice dimensions }\end{array}$ & $\begin{array}{c}\text { Estimate } \\
(\beta)\end{array}$ & S.E. & C.R. & P \\
\hline Affective commitment & $<---$ & Distributive justice & .320 & .060 & 6.102 & $<0.001^{*}$ \\
Continued commitment & $<---$ & Distributive justice & .105 & .064 & 1.583 & 0.114 \\
Normative commitment & $<---$ & Distributive justice & .234 & .055 & 4.062 & $<0.001^{*}$ \\
Affective commitment & $<---$ & Procedural justice & .245 & .077 & 2.749 & $0.006^{*}$ \\
Continued commitment & $<---$ & Procedural justice & .105 & .083 & .928 & 0.353 \\
Normative commitment & $<---$ & Procedural justice & .252 & .072 & 2.560 & $0.010^{*}$ \\
Affective commitment & $<---$ & Interactional justice & .201 & .063 & 2.358 & $0.018^{*}$ \\
Continued commitment & $<---$ & Interactional justice & .087 & .067 & .808 & 0.419 \\
Normative commitment & $<---$ & Interactional justice & .150 & .059 & 1.596 & 0.110 \\
\hline \hline
\end{tabular}

$* P<0.05$ (significant)

Estimate: Regression weights

S.E.: Statistical error

C.R.: Creative Ratio (Importance)

Model fitness criteria:

$\mathrm{CMIN} / \mathrm{DF}=3.347$

$\mathrm{GFI}=.927$

$\mathrm{PGFI}=.353$

$\mathrm{CFI}=.941$

RMSEA $=.152$

PCLOSE $=.005$

The selected indicators mean that the SEM model has a highly accepted fit criteria

Table (2): Correlation matrix between nurses' perception of organizational justice and organizational commitment

\begin{tabular}{||l|l|c|c|c|c||}
\hline \multirow{2}{*}{ Dimensions } & & $\begin{array}{c}\text { Distributive } \\
\text { justice }\end{array}$ & $\begin{array}{c}\text { Procedural } \\
\text { justice }\end{array}$ & $\begin{array}{c}\text { Interactional } \\
\text { justice }\end{array}$ & $\begin{array}{c}\text { Overall } \\
\text { organization } \\
\text { al justice }\end{array}$ \\
\hline \multirow{2}{*}{ Affective commitment } & $\mathrm{r}_{\mathrm{s}}$ & 0.495 & 0.577 & 0.552 & 0.623 \\
\cline { 2 - 6 } & $\mathrm{P}$ & $0.000^{*}$ & $0.000^{*}$ & $0.000^{*}$ & $0.000^{*}$ \\
\hline \multirow{2}{*}{$\begin{array}{l}\text { Continuance } \\
\text { commitment }\end{array}$} & $\mathrm{r}_{\mathrm{s}}$ & 0.103 & 0.165 & 0.163 & 0.175 \\
\cline { 2 - 6 } Normative \\
commitment & $\mathrm{P}$ & 0.085 & $0.006^{*}$ & $0.006^{*}$ & $0.003^{*}$ \\
\hline \multirow{2}{*}{$\begin{array}{l}\text { Overall Organizational } \\
\text { Commitment }\end{array}$} & $\mathrm{r}_{\mathrm{s}}$ & 0.364 & 0.495 & 0.461 & 0.528 \\
\cline { 2 - 6 } & $\mathrm{P}$ & $0.000^{*}$ & $0.000^{*}$ & $0.000^{*}$ & $0.000^{*}$ \\
\cline { 2 - 6 } & $\mathrm{P}$ & $0.000^{*}$ & $0.000^{*}$ & $0.000^{*}$ & $0.000^{*}$ \\
\hline
\end{tabular}

Rho: Spearman correlation co efficient

$* \mathrm{P}<0.05$ (significant) 
Nurses' Perception of Organizational Justice and Commitment

Table (3): Nurses' perception of organizational justice and organizational commitment at the two hospitals

\begin{tabular}{|c|c|c|c|c|c|c|c|c|c|c|c|c|c|c|c|c|c|}
\hline \multirow{2}{*}{\begin{tabular}{|l} 
Items \\
Organizational \\
justice
\end{tabular}} & \multicolumn{5}{|c|}{$\begin{array}{c}\text { Damanhur National Medical } \\
\text { Institute } \\
(\mathrm{N}=159)\end{array}$} & \multicolumn{5}{|c|}{$\begin{array}{l}\text { Kafr - AL Dawar General Hospital } \\
\qquad(\mathrm{N}=121)\end{array}$} & \multicolumn{5}{|c|}{$\begin{array}{c}\text { Total } \\
(\mathrm{N}=280)\end{array}$} & \multirow[t]{2}{*}{ Z } & \multirow[t]{2}{*}{$\mathrm{P}$} \\
\hline & $\begin{array}{c}\text { Mean } \\
\%\end{array}$ & SD & Min & Max & $\begin{array}{c}\text { Median } \\
\%\end{array}$ & $\begin{array}{c}\text { Mean } \\
\%\end{array}$ & SD & Min & Max & $\begin{array}{c}\text { Median } \\
\%\end{array}$ & $\begin{array}{l}\text { Mean } \\
\%\end{array}$ & SD & Min & Maxi & $\begin{array}{c}\text { Median } \\
\%\end{array}$ & & \\
\hline $\begin{array}{l}\text { - Distributive } \\
\text { justice }\end{array}$ & 45.9 & 13.1 & 20.00 & $\begin{array}{c}100.0 \\
0\end{array}$ & 46.0 & 42.3 & 11.1 & 20.00 & 82.00 & 42.0 & 44.4 & 12.4 & 20.00 & $\begin{array}{c}100.0 \\
0\end{array}$ & 44.0 & 2.3 & $0.021^{*}$ \\
\hline $\begin{array}{l}\text { - Procedural } \\
\text { justice }\end{array}$ & 50.3 & 15.9 & 17.78 & 88.89 & 48.9 & 46.8 & 16.7 & 17.78 & 84.44 & 44.4 & 48.8 & 16.3 & 17.78 & 88.89 & 46.7 & 1.7 & 0.078 \\
\hline $\begin{array}{l}\text { - Interactional } \\
\text { justice }\end{array}$ & 63.7 & 18.3 & 20.00 & $\begin{array}{c}100.0 \\
0\end{array}$ & 62.0 & 59.0 & 19.8 & 20.00 & $\begin{array}{c}100.0 \\
0\end{array}$ & 60.0 & 61.7 & 19.1 & 20.00 & $\begin{array}{c}100.0 \\
0\end{array}$ & 61.0 & 2.0 & $0.045^{*}$ \\
\hline $\begin{array}{l}\text { Overall } \\
\text { organizational } \\
\text { justice }\end{array}$ & 53.4 & 13.4 & 19.31 & 92.41 & 53.8 & 49.4 & 13.7 & 20.69 & 84.83 & 49.0 & 51.7 & 13.7 & 19.31 & 92.41 & 51.4 & 2.1 & $0.033^{*}$ \\
\hline \multicolumn{18}{|l|}{$\begin{array}{l}\text { Organizational } \\
\text { Commitment }\end{array}$} \\
\hline $\begin{array}{l}\text { - Affective } \\
\text { commitment }\end{array}$ & 47.2 & 13.8 & 20.00 & 80.00 & 44.4 & 43.2 & 14.5 & 17.78 & 86.87 & 42.2 & 45.4 & 14.2 & 17.78 & 86.87 & 42.2 & 2.3 & $0.021^{*}$ \\
\hline $\begin{array}{l}\text { - Continuance } \\
\text { commitment }\end{array}$ & 60.9 & 10.9 & 28.89 & 82.22 & 62.2 & 58.3 & 13.1 & 17.78 & 82.22 & 62.2 & 59.8 & 12.0 & 17.78 & 82.22 & 62.2 & 1.3 & 0.192 \\
\hline $\begin{array}{l}\text { - Normative } \\
\text { commitment }\end{array}$ & 52.7 & 12.1 & 26.67 & 82.22 & 53.3 & 50.2 & 11.6 & 26.67 & 82.22 & 48.9 & 51.6 & 11.9 & 26.67 & 82.22 & 51.1 & 1.8 & 0.071 \\
\hline $\begin{array}{l}\text { Overall } \\
\text { organizational } \\
\text { commitment }\end{array}$ & 60.3 & 11.2 & 30.00 & 87.50 & 59.2 & 56.9 & 11.4 & 29.17 & 86.67 & 57.5 & 58.8 & 11.4 & 29.17 & 87.50 & 58.3 & 2.4 & $0.018^{*}$ \\
\hline
\end{tabular}




\section{References}

1. Ogilvie J. R. The role of human resource management practices in predicting organizational commitment. Group and Organization Studies 1986; 11(4): 335359.

2. Chen S, Wu W, Chang C, Lin C, Kung J, Weng $\mathrm{H}$, Lin $\mathrm{Y}$, Lee S. Organizational justice, trust, and identification and their effects on organizational commitment in hospital nursing staff. BMC Health Services Research 2015; 15(363): 1-17.

3. Tomblom K.Y. The social psychology of distributive justice. In Scherer K. The nature and administration of justice: Interdisciplinary approaches. Cambridge. England: Cambridge University Press. 1990.

4. Elamin A.M, Alomaim N. Does organizational justice influence job satisfaction and self-perceived performance in Saudi Arabia work environment? International Management Review 2011; 7(1): 38-49.

5. Greenberg J. Organizational Justice: Yesterday, Today and Tomorrow. Journal of Management 1990; 16, 399-432.

6. Harvey S, Haines V.Y. Employer treatment of employees during a community crisis: The role of procedural and distributive justice. Journal of Business and Psychology 2005; 20(1): 53 68.

7. Cohen-Charash Y, Spector P. E. The role of justice in organizations: A metaanalysis. Organizational Behavior and Human Decision Processes 2001; 86(2): 278-321.

8. Saks A. Antecedents and consequences of employee engagement. Journal of Managerial Psychology 2006; 21 (7): 600 -619 .

9. Colquitt J. A. On the dimensionality of organizational justice: A construct validation of a measure. Journal of
Applied Psychology 2001; 86(3): 386400.

10. Faheem M.A, Mahmud N. The effects of organizational justice on workplace deviance and job satisfaction of employees: Evidence from a public sector hospital of Pakistan. Mediterranean Journal of Social Sciences 2015; 6(5):350.

11. Folger R, Konovsky M. A. Effects of procedural and distributive justice on reactions to pay raise decisions. Academy of Management Journal 1989; 32, 115-30.

12. Lambert E. G. The impact of job characteristics on correctional staff members. The Prison Journal 2004; 84(2): 208-227.

13. Meyer J.P, Allen N.J. Commitment in the workplace: Theory, research, and application. Thousand Oaks, CA: Sage Publications. 1997. pp. 150.

14. Gambino K. M. Motivation for entry, occupational commitment and intent to remain: A survey regarding registered nurse retention. Journal of Advanced Nursing 2010; 66(11):2532-2541.

15. Chang H, Shyu Y.L, Wong M, Friesner $\mathrm{D}$, Chu T, Teng C. Which Aspects of Professional Commitment Can Effectively Retain Nurses in the Nursing Profession? Journal of Nursing Scholarship 2015; 47(5): 469.

16. Lambert E.G, Hogan N. L, Griffin M. L. The impact of distributive and procedural justice on correctional staff job stress, job satisfaction, and organizational commitment. Journal of Criminal Justice 2007; 35(6): 644-56.

17. Gim G.C, Desa M.N. The impact of distributive justice, procedural justice, and affective commitment on turnover intention among public and private sector employees in Malaysia. International Journal of Social Science and Humanity 2014; 4(6): 478-492. 
18. Zein ElDin Y.K, Abd El Rahman R.M. The relationship between nurses' perceived pay equity and organizational commitment. Life Science Journal 2013; 10(2): 889-896.

19. Rezaiean A, Givi M.E, Givi H.E, Nasrabadi M.B. The relationship between organizational justice and organizational citizenship behaviors: The mediating role of organizational commitment, satisfaction and trust. Research Journal of Business Management 2010; 4(2): 112120.

20. Niehoff B.P, Moorman R.F. Justice as a mediator of the relationship between methods of monitoring and organizational citizenship behavior. Academy of Management Journal 1993; 36, 527-556.

21. Allen N.J, Meyer J.P. The measurement and antecedents of affective, continuance and normative commitment to the organization. The British Psychological Society 1990; 63 (1): 1-18.

22. Raza K, Rana N.A, Qadir M, Rana M.A. Relationship between distributive, procedural justice and organizational commitment: An empirical analysis on public sector of Pakistan. Middle-East Journal of Scientific Research 2013; 16(6): 878-883.

23. Lambert E.G, Hogan N.L. Association between distributive and procedural justice and life satisfaction among correctional staff: Research Note. Professional Issues in Criminal Justice 2011; 6(3 \& 4): 131-41.

24. Rai G.S. Impact of organizational justice on satisfaction, commitment and turnover intention: Can fair treatment by organizations make a difference in their workers' attitudes and behaviors? International Journal of Human Sciences 2013; 10(12): 260-284.

25. Meyer J.P, Allen N.J. A three-component conceptualization of organizational commitment. Human Resources Management Review 1991; 1(1): 61-89.

26. Wiener J. M, Squillace M. R, Anderson W. L, Khatutsky G. Why do they stay? Job tenure among certified nursing assistants in nursing homes. Gerontologist 2009; 49(2):198-210.

27. Forbes-Thompson S, Leiker T, Bleich M. R. High-performing and low performing nursing homes: A view from complexity science. Health Care Management Review 2007; 32(4): 341-351.

28. Jafari P, Motlagh F.S, Yarmohammadian M. H, Delavar A. Designing an adjusted model of organizational justice for educational system in Esfahan City (Iran). Procedia Social and Behavioral Sciences 2011; 15, 1696-1704. 